\title{
Potential Use of Banana Plant (Musa spp.) as Bio-sorbent Materials for Controlling Gaseous Pollutants
}

\author{
Sri Sumiyati ${ }^{1, *}$, Haryono Setiyo Huboyo ${ }^{1}$, Bimastyaji Surya Ramadan $^{1}$ \\ ${ }^{1}$ Department of Environmental Engineering, Faculty of Engineering, Diponegoro University, Semarang - Indonesia
}

\begin{abstract}
The use of organic waste as bio-sorbent has been carried out by many researchers in the world. Furthermore, the utilization of plants for treating wastewater is also commonly found in various environmental applications. Nevertheless, a review of the ability of banana plants (Musa spp.) as biosorbent to eliminate gaseous pollutants is rarely found and has not been fully understood. In this paper, lignocellulosic biomass from banana plants (bark, stem, leaves, peels, etc) was identified and reviewed. Sorption potential was discussed and taken from various literature which then evaluated to discuss the potential and ability of banana plants as sorbent material for treating gaseous pollutants. Assessment and measurement methods were also discussed to obtain the best sorbent in removing gaseous pollutants. This research was conducted by reviewing scientific articles that discussed the use of lignocellulosic materials derived from banana plants for absorbing various gases. Almost all articles described the manufacture of adsorbents from banana plants that were used to treat wastewater but not many researchers have tried to develop a commercially adsorbent for gas-shaped pollutants. This research is expected to provide essential information for the readers to develop advanced materials used to control environmental pollution especially gaseous pollutants.
\end{abstract}

Keyword: Banana; gaseous pollutants; bio-sorption.

\section{Introduction}

Gaseous pollutant has high mobility, fast and difficult to control and visualize. Some gases such as $\mathrm{H}_{2} \mathrm{~S}, \mathrm{~N}_{2} \mathrm{O}$ contained in biogas or ambient air are indicated to have high levels of toxicity and very detrimental [1-3]. To overcome these problems, several air pollution control technologies can be applied. Adsorption is the treatment that most often used in dealing with gas pollution. Gas pollutants have a micropore molecular size of $<2 \mathrm{~nm}$ so that the filtration method alone is not enough to overcome the impact [4]. The use of activated carbon in air pollution control is very commonly used [3-5]. Activated carbon pores have sufficient size for gas adsorption and have a large surface area so that a rapid reaction occurs in controlling air pollution $[6,7]$.

Indonesia has many types of exotic fruits that are typically found in tropical countries. A large amount of production places Indonesia in the ranks of the world's top 20 fruit producers. Banana is an annual fruit plant that ranks first in the leading commodities in Indonesia with a production rate of 7,299,275 tons above the rate of production of mangoes, oranges, pineapples, and durians [8]. In addition to the fruit, some parts of banana plants such as banana leaves are widely used by the community as food wrappers. A small portion of banana stems are only used as fodder, and most of it is wasted. Stems, leaves, and waste of banana peel are one of the ingredients that have the potential as activated carbon because of its cellulose content which is around 40\% [9].

The use of banana plants to reduce various types of pollutants in the environment has been discussed in depth by several researchers. In general, activated carbon/activated biochar produced from a variety of biomass (including bananas) has been reviewed in detail by Nor et al. [10]. In this review, it was also mentioned the preparation and activation method of activated carbon from lignocellulose biomass for removal of $\mathrm{SO}_{2}$, $\mathrm{NO}_{2}, \mathrm{H}_{2} \mathrm{~S}$, and VOC [10]. Suhas et al. [11] also stated that bananas were one of the lignocellulosic materials which have a greater adsorption capacity than oranges. Therefore, many researchers were often found using banana waste as an adsorbent precursor material. Ahmad and Danish [12] assume that banana waste used as an adsorbent can remove metal ions and emerging contaminants such as pesticides, water-soluble radioactive nuclides and inorganic anions.

There is no review article specifically discussing and summarizing the potential use of waste from the banana plant as advanced material for the adsorption of gasshaped pollutants. Desk study has been conducted and explored through on-line search from academic databases such as google scholar, sciencedirect.com, and scopus.com using banana + waste + air + gaseous + pollution/pollutant + adsorption. We found 56 articles related to banana as pollutant adsorbent. The purpose of this paper is to find the potential use of banana plants as

\footnotetext{
*orresponding author: srisumiyati71@gmail.com
} 
gas adsorbents. In addition, an analysis of the production of activated carbon from banana plants and the mechanisms that may occur in gas removal is also carried out. The authors hope this paper can be used as main references for further research related to gas and particulate matter adsorption using banana trees as bioadsorbent.

\section{Banana Trees and Its Potential Uses for Environmental Application}

Banana plant is one of the large leafy tropical plants originating from the Musa spp. clan, including the tribe of Musaceae. In Indonesia, bananas are one of the main and superior commodities along with other fruits such as mango and durian. Banana stems are pseudo-stems consisting of banana midribs with large water content, cellulose, polysaccharide (inulin) and glucose. This is usually left in the garden, used as a rope for tobacco processing or reprocessed into compost [13].

Until now, many researchers have used the waste from banana plants as an alternative to innovative food, alternative energy sources and important materials for water and wastewater treatment. Some researchers use banana peels as antidepressant candy, milk mixture, and animal feed [14, 15]. Zhang et al. [16] stated that banana peels can be used as an alternative for battery fillers. Banana waste can be taken to make bioethanol [17]. Banana also can be used as a processed food product that is effective in treating several diseases such as intestinal bleeding and dysentery. Banana waste can also be used as an alternative to raw materials for making bioethanol and supplementary materials to increase biogas production [18]. All parts of the banana plant also have the potential to be used as an adsorbent for pollutants such as heavy metals, coloring agents, domestic liquid waste, and even radioactive minerals in the liquid phase [12].

Bananas are used as a source of cellulose because they have a high level of production, produced every year and only $12 \%$ of the weight of the plants consumed [19]. This results in a large volume of residue which has the potential to be used as a raw material in the development of new products and reducing the waste generation in the environment. In addition, banana stems have a low lignin content [20], banana stems were also chosen as a source of cellulose by Noremberg et al. [21] because banana stems were rich in cells with low-fat content, which increased the quality of the product. The consumption of banana plants produces residues in the form of stems which are usually thrown away. Basically, banana peels and stem can still be used as a more useful raw material for products by utilizing the lignocellulose content $[19,22]$. This type of material can also be used as bio-energy through biochemical or thermochemical processes or as reinforcing agents in biodegradable composites [23].

Lignocellulose has high biocompatibility, biodegradability, and low toxicity. In addition, this material is also renewable and has high economic value [24]. Cellulose can be processed using various techniques to obtain varied products such as microcrystalline and nanofiber using the process of acid hydrolysis, enzymatic hydrolysis or using high energy $[25,26]$. Cellulose and its derivatives are widely used as composites that have been widely studied to synthesis advanced materials such as carbon nanotubes for various purposes [16, 27, 28].

\section{Activated Carbon Production}

Activated carbon is an amorphous carbon material that has a high surface area, and has high $\mathrm{CO}_{2}$ adsorption capacity so it is suitable to be applied on a large scale [29]. Activated carbon is very flexible, stable at high temperatures and pressures, stages of radiation, moisture, alkaline, and acidic solutions. In addition, material regeneration only requires low temperatures than zeolites [30]. The development of lignocellulose activated carbon technology will increase the conversion of waste into useful materials. Lignocellulose is one of the right precursors to be used as activated carbon because it has a very high surface area and large micropore volume. Lignocellulose activated carbon applied in controlling air pollution is highly dependent on the activated carbon adsorption capacity. Therefore, it is necessary to modify the activation of raw carbon material [10].

Lignocellulose biomass consists of three components, namely, cellulose, hemicellulose, and lignin. The main component in lignocellulose biomass is lignin which plays an important role in the adsorption process. Lignin-based biomass is the most abundant renewable carbon source after cellulose with a world production of 40-50 million tons/year [11]. Lignocellulose biomass is the right choice for use as activated carbon production [31]. The production of activated carbon can indirectly contribute to the reduction of waste in the environment and reduce costs for the production of activated carbon because the raw material used comes from waste.

Commonly, activated carbon is produced through two processes, namely carbonization, and activation [32]. During carbonization, the activated carbon precursor decomposes, the density decreases, while the porosity will increase. During activation, the pores become wider and the porosity network is well-formed. Based on the type of activating material, activation is divided into two categories namely thermal (physical) or chemical activation. In the first process, the activated carbon precursor is gasification by $\mathrm{CO}_{2}$ or $\mathrm{H}_{2} \mathrm{O}$ at $800-9000^{\circ} \mathrm{C}$. Then in the second process chemical carbonization can be carried out with metal oxides, alkali metals, or acids. Chemicals that are often used in the activation process are $\mathrm{ZnCl} 2$ and $\mathrm{KOH}$. Therefore, $\mathrm{H}_{3} \mathrm{PO}_{4}, \mathrm{NaOH}, \mathrm{CaCl}_{2}$, $\mathrm{H}_{2} \mathrm{SO}_{4}, \mathrm{~K}_{2} \mathrm{CO}_{3}, \mathrm{Cu}\left(\mathrm{NO}_{3}\right)_{2}$, and $\mathrm{NH}_{3}$ can also be used [33].

Biochar is a carbon material that represents charcoal made from biomass which is heated at high temperatures in the absence of oxygen (pyrolysis) [34]. Biochar has been widely applied and successful for soil improvement, water treatment, wastewater treatment, renewable energy, and as a catalyst because it has high porosity [35]. However, some limited researchers use 
biochar to eliminate gas pollution or hazardous materials in the form of gases in the environment [36]. Khan et al. (2019) assess various types of biochar to remove benzene gas. Adsorption capacity using various types of biochar; such as conventional biochar (made from paper mill mud with a slow pyrolysis process), biochar using alkali activation and co-activation processes, and incorporating biochar composite materials to improve biochar performance. Furthermore, it was observed the isotherm profile in terms of maximum capacity in the low/high pressure ranges with recharge volumes (BTV 5, 10 and $50 \%$ ) to determine and assess the performance of the adsorbent. The results of his research showed that the gasification of biochar with $\mathrm{KOH}$ activation was suitable to maintain air quality [4].

\section{Gaseous Pollutants}

Air pollution is increasingly damaging the quality of the atmosphere due to emissions from rapidly developing industrial activities and increasing population growth. Therefore, several strategies need to be carried out to reduce air pollution. One method of controlling air pollution is by using activated carbon/biochar which is produced by banana waste processing. The following are some gas-shaped pollutants that may be removed using activated carbon/biochar.

\subsection{Hydrogen Sulphide}

$\mathrm{H}_{2} \mathrm{~S}$ gas is an air pollutant, one of which comes from agriculture and industry. Because of the nature of its toxicity, $\mathrm{H}_{2} \mathrm{~S}$ gas must be reduced so that its concentration is below the maximum limit. Hydrogen sulphide $\left(\mathrm{H}_{2} \mathrm{~S}\right)$ is a colorless, highly toxic, flammable gas that has the characteristic odor of rotten eggs. This gas can cause adverse effects on health, especially in the respiratory tract [37]. $\mathrm{H}_{2} \mathrm{~S}$ is produced from the decay process of organic materials containing sulphide by anaerobic bacteria. Also, as a result of reduction with anaerobic conditions against sulphate by microorganisms and as a pollutant of gases released from geothermal water. Pollutants from the chemical industry, paper mills, textile mills, and leather tanners can contain $\mathrm{H}_{2} \mathrm{~S}$ [38].

Hydrogen sulphide $\left(\mathrm{H}_{2} \mathrm{~S}\right)$ is one of the gases that cause odour. When speaking of landfills, sulphide acid gas is a gas produced from anaerobic sulphate conversion process by sulphate reducing bacteria (SRB). However, $\mathrm{H}_{2} \mathrm{~S}$ can also occur in aerobic conditions [39]. A mechanism for $\mathrm{H}_{2} \mathrm{~S}$ removal is to use an oxidationreduction mechanism in the presence of oxygen as a strong oxidizer. $\mathrm{H}_{2} \mathrm{~S}$ can be converted to sulphur oxide $\left(\mathrm{SO}_{2}\right)$ and sulfuric acid $\left(\mathrm{H}_{2} \mathrm{SO}_{4}\right)$. In addition, the removal of sulphate acid can also be through the detailed mechanism of adsorption by zeolite discussed by Sigot et al (2016) [2]. The mechanism is as follows:

1. $\mathrm{H}_{2} \mathrm{~S}$ are adsorbed on the surface of the adsorbent

$$
\mathrm{H}_{2} \mathrm{~S}_{(\mathrm{g})} \rightarrow \mathrm{H}_{2} \mathrm{~S}_{(\text {ads })}
$$

2. $\mathrm{H}_{2} \mathrm{~S}$ are dissolved in water in the adsorbent pore

$$
\mathrm{H}_{2} \mathrm{~S}_{(\mathrm{ads})} \rightarrow \mathrm{H}_{2} \mathrm{~S}_{(\mathrm{aq})}
$$

3. $\mathrm{H}_{2} \mathrm{~S}$ are dissociated into the water layer

$$
\mathrm{H}_{2} \mathrm{~S}_{(\mathrm{aq})}+\mathrm{H}_{2} \mathrm{O}_{(\mathrm{l})} \rightarrow \mathrm{HS}_{(\mathrm{aq})}^{-}+\mathrm{H}_{3} \mathrm{O}_{(\mathrm{l})}^{+}
$$

4.HS-oxidation by adsorbed oxygen

$$
\mathrm{HS}_{(\mathrm{aq})}^{-}+\mathrm{O}_{(\mathrm{ads})} \rightarrow \mathrm{S}_{(\mathrm{ads})}+\mathrm{OH}_{(\mathrm{aq})}^{-}
$$

5.Polymer formation

$$
\mathrm{xS}_{(\mathrm{ads})} \rightarrow \mathrm{S}_{\mathrm{x}(\mathrm{ads})}
$$

The success of various technologies and $\mathrm{H}_{2} \mathrm{~S}$ removal methods has been proven by several research $[1,2,37]$. However, the method or technique that is often used and successfully applied is by the use of activated carbon through the mechanism of adsorption [40-42]. It is known that some parts of plants such as oil palm, coconut shell and red pine can be used as adsorbents [10]. The coconut shell adsorbent is the most commonly found adsorbent and proven to be able to purify biogas from $\mathrm{H}_{2} \mathrm{~S}$ with a concentration of 2,400 ppm. However, there are no studies specifically using adsorbents from parts of banana plants in $\mathrm{H}_{2} \mathrm{~S}$ gas removal. So far, the utilization of waste from banana plants as adsorbent has been successfully treated any kind of wastewater [12]. Hydrogen sulfide can be analyzed using spectrophotometer. The test method is referring to JIS K 0108-1995. In principle, hydrogen sulfide from immovable sources are poured into absorbent solution. Then hydrogen sulfide is reacted with p-amino dimethyl aniline and iron (III) in acid solution to form methylene blue compounds and analyzed using spectrophotometer at $670 \mathrm{~nm}$ of wavelength.

\subsection{Sulphur Dioxide}

Sulphur dioxide is one of the main causes of acid rain which needs attention because it can be one of the serious global environmental problems. Adsorption of $\mathrm{SO}_{2}$ gas using activated carbon material has been carried out by many researchers [43, 44]. Most of the production of activated carbon is carried out using chemical methods. Chemical methods are known to increase $\mathrm{SO}_{2}$ removal because the surface of activated carbon is surrounded by chemical compounds that can exchange pollutants with ions that are environmentally friendly (ion exchange). $\mathrm{SO}_{2}$ allowance can also be done by physical and chemical adsorption. Calcium oxide contained in almond skin and wood is known to increase $\mathrm{SO}_{2}$ removal. Possible effective methods to use to activate carbon are physical mixing, ion exchange, and impregnation [45].

$\mathrm{SO}_{2}$ removal by lignocellulosic-based materials has also been carried out by Yang and Lua [46] by utilizing pistachio shells as activated carbon by carrying out a physical activation method using $\mathrm{CO}_{2}$ and steam at $900^{\circ} \mathrm{C}$, followed by chemical activation using $\mathrm{NaOH}$. Yang and Lua have applied kinetic, micropore, macropore, surface diffusion, and nonlinear isotherm 
adsorption models resulting in an adsorption capacity of $89.6 \mathrm{mg} \mathrm{SO}_{2} / \mathrm{g}$ [47].

\subsection{Nitrous Pollutant $\left(\mathrm{NH}_{3}, \mathrm{~N}_{2} \mathrm{O}, \mathrm{NO}_{2}\right)$}

Activated carbon and biochar from banana plants have also been used successfully to minimize $\mathrm{NO}_{2}$ emissions [48]. Kante et al. [49] have used activated carbon derived from wood using chemical recharge methods such as sodium, cerium, and lanthanum chloride. These chemical agents produce a higher $\mathrm{NO}_{2}$ adsorption capacity. The adsorption capacity for sodium chloride was $283 \mathrm{mg} \mathrm{NO} / \mathrm{g}$ whereas for lanthanum chloride it had a lower adsorption capacity of $143 \mathrm{mg} \mathrm{NO} / \mathrm{g} . \mathrm{NO}_{2}$ removal is also carried out using walnut shell as activated carbon. The activation method used is to utilize potassium hydroxide $(\mathrm{KOH})$ rather than $\mathrm{CO}_{2}$ because it can increase the higher micropore volume. Activation using $\mathrm{KOH}$ resulted in an adsorption capacity of $66.3 \mathrm{mg}$ $\mathrm{NO} 2 / \mathrm{g}$, while activation using $\mathrm{CO}_{2}$ had a lower adsorption capacity of $58.1 \mathrm{mg} \mathrm{NO} / \mathrm{g}$. Activated carbon in steam at a temperature of $800^{\circ} \mathrm{C}$ has a surface area five times greater and a greater total pore volume than the sample of activated carbon in steam at $400^{\circ} \mathrm{C}$ [49]. This shows that the type of activation can affect the increase in adsorption capacity.

Thangarajan et al. [5] concluded that Dicyandiamide (DCD) was more effective than biochar in an effort to reduce $\mathrm{N} 2 \mathrm{O}$ emissions from source $\mathrm{N}$ which is in agricultural soils. DCD is most widely used as NI (Nitrification Inhibitors) because it is very effective in inhibiting nitrification and reducing $\mathrm{N} 2 \mathrm{O}$ emissions. However, the addition of DCD results in an increase in $\mathrm{NH}_{3}$ emissions from the soil. Although the application of DCD results in a much higher reduction in N2O emissions compared to biochar, biochar is more effective in reducing total $\mathrm{N}$ loss through ammonia emissions $\left(\mathrm{NH}_{3}\right.$ and $\mathrm{N}_{2} \mathrm{O}$ i.e. $25 \%$ ). Biochar has a good absorption capacity so that it can reduce volatilization of $\mathrm{NH}_{3}$ [5]. Several studies and studies in the field have found that there is a significant reduction in $\mathrm{N}_{2} \mathrm{O}$ emissions if biochar is used as soil amendments [50].

\subsection{Particulate Matter and Volatile Organic Carbon}

Particulate matter and organic volatile compounds (VOCs) are the most common indoor air pollutants, which becoming problems throughout the world because they have a serious impact on human health [51]. One of them is $\mathrm{PM}_{2.5}$ which contains complex components including hard inorganic PM particles and soft PM particles such as organic carbon and elemental carbon [52] which are capable of causing cardiovascular disease and respiratory disorders. Formaldehyde is an air pollutant of volatile organic compounds (VOCs) produced from the chemical process industry, building materials, cosmetics, and furniture / decoration materials [53].

Utilization of biomass into a nanofiber membrane to filter particulate matter and capture VOC gas has been tested by Zhu et al. [54]. In the study, it was stated that ZIF-8@SiO2 composite nanofiber membrane could be used as particulate matter capture and gas adsorption. $\mathrm{SiO} 2$ nanofiber membranes are very flexible because they are made using the electrospinning method, while the zeolitic imidazolate framework-8 (ZIF-8) nanocrystal is planted in nanofibers to control crystallization with a counter-diffusion system. With the presence of ZIF-8 @ $\mathrm{SiO} 2$ composite membranes the efficiency of particulate matter removal is higher and formaldehyde is very well adsorbed so that it is promising to be used as an air purification medium that has diverse pollutants [54]. Other VOCs such as benzene (including toluene, ethylbenzene and xylene) are used in bitumen production, the petrochemical industry, and the synthesis of various carbon products, for example; plastics, synthetic fiber and pesticides [55]. Benzene in the air is a pollutant that is very dangerous at certain concentrations (ppm). Khan et al. [4] explored benzene adsorption using conventional biochar, composite biochar, biochar gasification from mixed raw materials, biochar gasification from one of the raw materials, $\mathrm{KOH}$ activated biochar, and activated carbon under conditions of ambient pressure and temperature.

\subsection{Carbon Dioxide}

Carbon by-products from the biomass gasification process are commonly known as biochar. At present, biochar can be processed into activated carbon because it has similar characteristics in terms of physics - chemistry and its formation mechanism. Benedetti et al. [3] stated that biochar is very good for use as a substitute for activated carbon in $\mathrm{CO}_{2}$ adsorption. This study uses 5 char with different characteristics of composition, ash content, porosity and morphology associated with different $\mathrm{CO}_{2}$ adsorption capacities. The results showed that the porosity of the material has a relevant role in the adsorption process, namely the lower the porosity, the lower the adsorption of pollutants (low adsorption capacity) and vice versa. Other parameters such as the chemical surface and pore size distribution also affect $\mathrm{CO}_{2}$ adsorption capacity [56, 57]. Chemical activators can form the desired chemical surface and a more uniform pore size distribution. Recycling char as an active carbon material has significant potential in reducing industrial waste and reducing uncontrolled solid waste disposal in the environment. In addition, it also reduces costs in creating environmentally friendly activated carbon technology [3].

\section{Conclusion}

A review of the potential use of banana plants has been carried out. The presence of lignocellulose contained in banana plants makes it suitable for conversion into bioadsorbent harmful pollutant gases. Several conventional adsorbents are used to absorb pollutant gases and impurities such as hydrogen sulphide, sulphur dioxide, nitrous oxide, particulate matter, carbon dioxide and VOC have been investigated by many researchers. 
However, the used of banana plants as a commercial adsorbent in overcoming air pollution is not yet available. The potential of research and patents related to this material is still large enough to be investigated because the generation of banana waste, especially in Indonesia and other exporters of banana countries, is quite large and has not been widely explored.

\section{Acknowledgement}

The authors would like to thanks to Faculty of Engineering, Diponegoro University that financially supporting this research under RKAT Scheme Number $167 / \mathrm{UN} 7.53 / \mathrm{HK} / 2019$ for strategic research in 2019 of Financial Year.

\section{References}

1. Y. Long, Y. Fang, D. Shen, H. Feng, T. Chen, Sci. Rep. 6(1), 38103 (2016)

2. L. Sigot, G. Ducom, P. Germain, Chem. Eng. J., 287, 47-53 (2016)

3. V. Benedetti, E. Cordioli, F. Patuzzi, M. Baratieri, J. $\mathrm{CO}_{2}$ Util. 33, 46-54, (2019)

4. A. Khan et al., Chem. Eng. J. 361, 1576-1585 (2019)

5. R. Thangarajan, et al., Sci. Total Environ. 612, 257-268 (2018)

6. P. Nowicki, R. Pietrzak, H. Wachowska, Catal. Today 150(1-2), 107-114 (2010)

7. D.P. Vargas, L. Giraldo, J. Silvestre-Albero, J.C. Moreno-Piraján, Adsorption 17(3), 497-504 (2011)

8. P.L. Hariani, F. Riyanti, R.D. Asmara, Molekul 11(1), 135 (2016)

9. D. Mohapatra, S. Mishra, N. Sutar, J. Sci. Ind. Res. 69(5), 323-329 (2010)

10. N.M. Nor, L.C. Lau, K.T. Lee, A.R. Mohamed, J. Environ. Chem. Eng. 1(4), 658-666 (2013)

11. Suhas, V.K. Gupta, P.J.M. Carrott, R. Singh, M. Chaudhary, S. Kushwaha, Bioresour. Technol. 216, 1066-1076 (2016)

12. T. Ahmad, M. Danish, J. Environ. Manage. 206, 330-348 (2018)

13. H. Alwi, J. Idris, M. Musa, K.H.K. Hamid, J. Chem. 2013, 1-7 (2013)

14. P. Gurumallesh, B. Ramakrishnan, B. Dhurai, Int. J. Biol. Macromol. 134, 527-535 (2019)

15. A.L.D. Batista et al., J. Funct. Foods 38, 242-250 (2017)

16. Y. Zhang, Z. Gao, N. Song, X. Li, Electrochimica Acta 222, 1257-1266 (2016)

17. A. B. Guerrero, I. Ballesteros, M. Ballesteros, Fuel 213, 176-185 (2018)

18. A.C. Lantang, J. Abidjulu, H.F. Aritonang, J. MIPA 6(2), 55 (2017)

19. S. Elanthikkal, U. Gopalakrishnapanicker, S. Varghese, J.T. Guthrie, Carbohydr. Polym. 80(3), 852-859 (2010)

20. N. Cordeiro, M.N. Belgacem, I.C. Torres, J.C.V.P. Moura, Ind. Crops Prod. 19(2), 147-154 (2004)
21. B.S. Noremberg et al., Sens. Actuators B Chem. 240, 459-467 (2017)

22. P. Khawas, S.C. Deka, Carbohydr. Polym. 137, 608-616 (2016)

23. R. Moriana, F. Vilaplana, S. Karlsson, A. Ribes, Carbohydr. Polym. 112, 422-431 (2014)

24. M. Jorfi, E.J. Foster, J. Appl. Polym. Sci. 132, 14 (2015)

25. S.N. Sari A. Melati, Mater. Today Proc. 13, 165168 (2019)

26. R.K. Mishra, A. Sabu, S.K. Tiwari, J. Saudi Chem. Soc. 22(8), 949-978 (2018)

27. A. Mohammadi, P. Veisi, J. Environ. Chem. Eng. 6(4), 4634-4643 (2018)

28. M. Xue, W. Lu, C. Chen, Y. Tan, B. Li, C. Zhang, Mater. Res. Bull. 112, 269-280 (2019)

29. M. Sevilla, A.B. Fuertes, J. Colloid Interface Sci. 366(1), 147-154 (2012)

30. B.S. Caglayan, A.E. Aksoylu, J. Hazard. Mater. 252-253, 19-28 (2013)

31. W. Li et al., J. Taiwan Inst. Chem. Eng. 64, 166172 (2016)

32. V. Benedetti, F. Patuzzi, M. Baratieri, Appl. Energy 227, 92-99 (2018)

33. Yuliusman, J. Sinto, Y.W. Nugroho, H.I. Naf'an, E3S Web of Conf. 67, 03020 (2018)

34. S. Weldon, D.P. Rasse, A. Budai, O. Tomic, P. Dörsch, Soil Biol. Biochem. 135, 173-183 (2019)

35. J. Wang, S. Wang, J. Clean. Prod. 227, 1002-1022 (2019)

36. X. Zhang et al., Bioresour. Technol. 245, 606-614 (2017)

37. Y. Wang, Z. Wang, J. Pan, Y. Liu, Fuel 239, 70-75 (2019)

38. S.L.M. Rubright, L.L. Pearce, J. Peterson, Nitric Oxide 71, 1-13 (2017)

39. Y. Long, Y. Fang, D. Shen, H. Feng, T. Chen, Sci. Rep., 6(1), 38103 (2016)

40. T. Mochizuki, M. Kubota, H. Matsuda, L.F. D'Elia Camacho, Fuel Process. Technol. 144, 164-169 (2016)

41. M. Sun et al., Fuel Process. Technol. 191, 121-128 (2019)

42. F. Shen, J. Liu, Z. Zhang, Y. Dong, C. Gu, Fuel Process. Technol. 171, 258-264 (2018)

43. A.M.B. Furtado, Y. Wang, M.D. LeVan 165, 4854 (2013)

44. S. Ge, Z. Liu, Y. Furuta, W. Peng, Saudi J. Biol. Sci. 24(6), 1370-1374 (2017)

45. M.C. Macías-Pérez, M.A. Lillo-Ródenas, A. Bueno-López, C. Salinas-Martínez de Lecea, A. Linares-Solano, Fuel 87(12), 2544-2550 (2008)

46. T. Yang, A.C. Lua, Microporous Mesoporous Mater. 63(1-3), 113-124 (2003)

47. A.C. Lua, T. Yang, Chem. Eng. J., 155(1-2), 175183 (2009)

48. T.A. Sial et al., Process Saf. Environ. Prot. 122, 366-377 (2019)

49. K. Kante, E. Deliyanni, T.J. Bandosz, J. Hazard. Mater. 165(1-3), 704-713 (2009) 
50. F.A. Petter, L. Borges de Lima, B.H. Marimon Júnior, L. Alves de Morais, B.S. Marimon, J. Environ. Manage. 169, 27-33 (2016)

51. C. Norris et al., Chemosphere 231, 256-268 (2019)

52. A. Chafidz, W. Astuti, D. Hartanto, A. S. Mutia, P.R. Sari, Matec Web of Conf. 154, 01021 (2018)

53. T. Salthammer, Build. Environ. 150, 219-232 (2019)

54. Q. Zhu, X. Tang, S. Feng, Z. Zhong, J. Yao, Z. Yao, J. Membr. Sci. 581, 252-261 (2019)

55. A. Carvajal, I. Akmirza, D. Navia, R. Pérez, R. Muñoz, R. Lebrero, J. Environ. Manage. 214, 125$136(2018)$

56. A.A. Niya, T.E. Rufford, Z. Zhu., Energy Fuels. 30(9), 7298 - 7309 (2016)

57. A. Borhan, S. Thangamuthu, M.F. Taha, A.N. Ramdan, AIP Conf. Proc. 1674, 020002 (2015) 